\title{
Time-dependent integrity during storage of natural surface water samples for the trace analysis of pharmaceutical products, feminizing hormones and pesticides
}

\author{
Khadija Aboulfadl 11,2, Cyril De Potter ${ }^{1}$, Michèle Prévost ${ }^{2}$ and Sébastien Sauvé*1
}

\begin{abstract}
Monitoring and analysis of trace contaminants such as pharmaceuticals and pesticides require the preservation of the samples before they can be quantified using the appropriate analytical methods. Our objective is to determine the sample shelf life to insure proper quantification of ultratrace contaminants. To this end, we tested the stability of a variety of pharmaceutical products including caffeine, natural steroids, and selected pesticides under refrigerated storage conditions. The analysis was performed using multi-residue methods using an on-line solid-phase extraction combined with liquid chromatography tandem mass spectrometry (SPE-LC-MS/MS) in the selected reaction monitoring mode. After 21 days of storage, no significant difference in the recoveries was observed compared to day 0 for pharmaceutical products, while for pesticides, significant losses occurred for DIA and simazine after 10 days (14\% and $17 \%$ reduction respectively) and a statistically significant decrease in the recovery was noted for cyanazine (78\% disappearance). However, the estrogen and progestogen steroids were unstable during storage. The disappearance rates obtained after 21 days of storage vary from 63 to $72 \%$ for the feminizing hormones. Overall, pharmaceuticals and pesticides seem to be stable for refrigerated storage for up to about 10 days (except cyanazine) and steroidal hormones can be quite sensitive to degradation and should not be stored for more than a few days.
\end{abstract}

\section{Introduction}

The simple way to insure the integrity of collected samples would be to keep them refrigerated and analyze them within $24 \mathrm{~h}$ of collection before unwanted chemical, physical and biological alterations of the samples are observed. Unfortunately, those analyses are often dependent on heavily solicited mass spectrometry instruments and considering various logistical constraints, it is often impossible to analyze such samples within a day. Then the question arises: how long can we store those samples before we analyze them for ultra traces of contaminants (sometimes to concentration below the $\mathrm{ng}^{-1}$ range).

To address this, we have performed simultaneous stability studies of pharmaceuticals (naproxen, gemfibrozil, carbamazepine, trimetroprim, caffeine), steroidal hormones both estrogens (estriol, estradiol, 17 $\alpha$-ethy-

* Correspondence: sebastien.sauve@umontreal.ca

1 Département de chimie, Université de Montréal, Montréal, QC, Canada Full list of author information is available at the end of the article nilestradiol, estrone) and progestogens (norethindrone, medroxyprogesterone, progesterone, norgestrel) and pesticides (deethylatrazine (DEA), deisopropylatrazine (DIA), simazine, atrazine and cyanazine). The major characteristics of the investigated products are shown in Table 1.

The main factors affecting the stability of analytes in water samples include hydrolysis, photolysis, physical adsorption or release to or from suspended particulates, chemical degradation by oxidative free-radicals such as alkylperoxy and hydroxyl radicals present in natural waters, or microbial degradation [1], the nature of the sample-container, solubility, vapor pressure and the conditions of storage (temperature, darkness, use of preservatives, time interval between sampling and analysis [2]). Also, the stability of the analytes can be linked to their vapor pressure and water solubility. Indeed, in the literature, it is reported that compounds having a low vapor pressure and medium water solubility (up to $40 \mathrm{mg} \mathrm{L}^{-1}$ )<smiles>c1ccccc1</smiles> 
Table 1: Target compounds, use, molecular weight (MW), pKa, water solubility and vapor pressure.

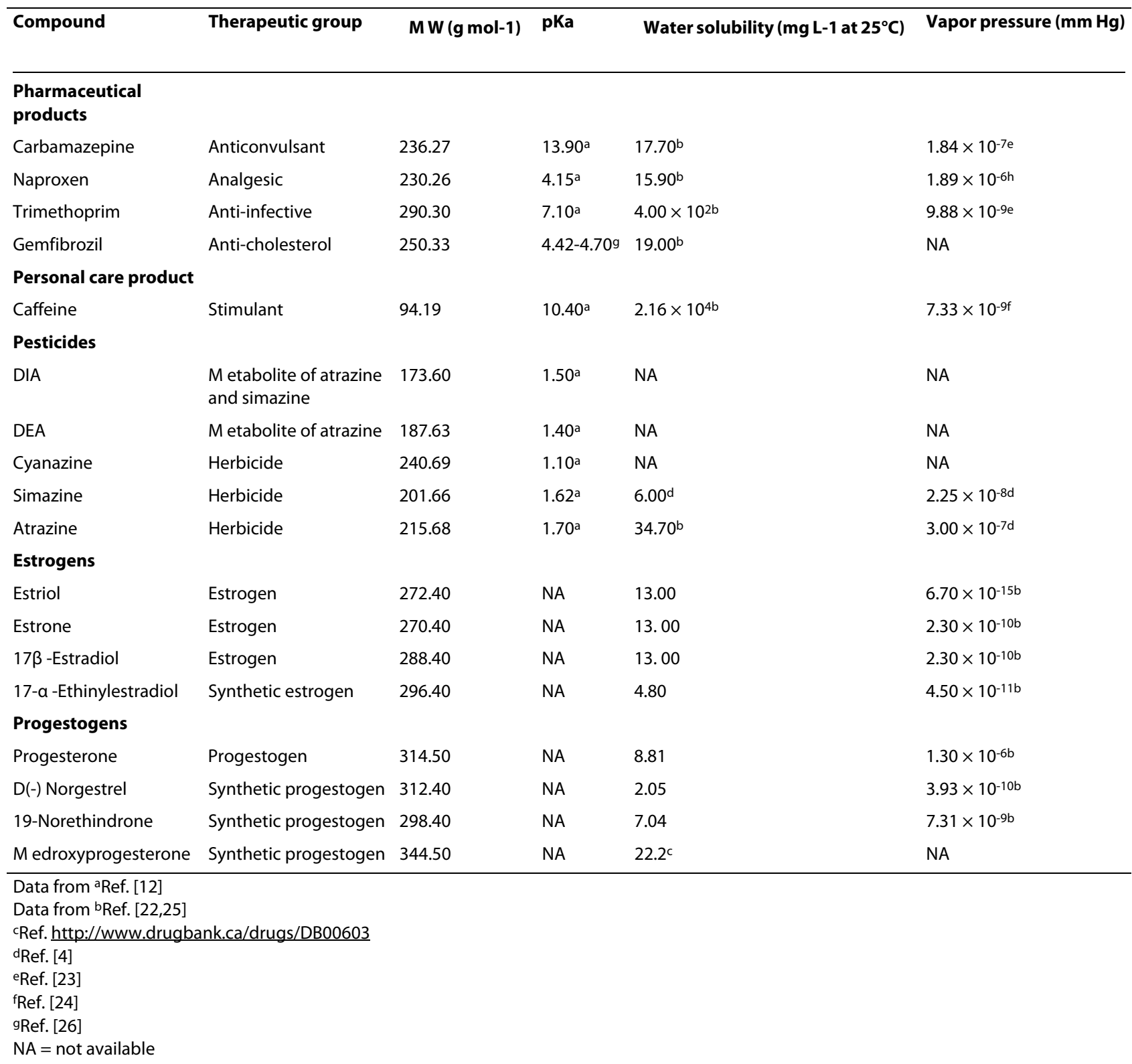

are stable while poor stability is attributed to compounds having high water solubility (up to $700 \mathrm{mg} \mathrm{L}^{-1}$ ), or relatively high vapor pressure [3].

The most extensive stability studies found in the literature have focused on pesticides. Such research has confirmed that many pesticides are unstable in natural waters, depending on microbial degradation, hydrolysis and photolysis [4-6]. To compensate this lack of stability, various stabilizers or preservatives have been added to aqueous samples, e.g., methanol [7], dichloromethane, dilute acid solutions or $\mathrm{HgCl}_{2}$ [5] to retard the decomposition of the constituent chemicals. Studies on alternative pesticide stabilization techniques, including the use of freeze-drying, have been published. Again, the results showed that the stability of the compounds depends on their water solubility and vapor pressure.

Other papers have demonstrated that solid-phase extraction (SPE) is a good alternative for the storage of pesticides pre-concentrated from water samples [3,8]. For example, de la Colina et al. [5] have indicated that storage of different pesticide classes on the $\mathrm{C} 18$ silica-gel surface of solid-phase cartridges for 30 days at $4^{\circ} \mathrm{C}$ or $-18^{\circ} \mathrm{C}$ is effective for 17 out of the 23 pesticides studied. Sabik et al. [8] have shown that it is possible to preserve herbicides (e.g DEA, DIA, cyanazine, simazine and atrazine) and degradation products in large volumes of surface water, 
without physical, chemical or biological alteration of these compounds, by using GCB cartridges (large-particle-size Carbopack B 60-80 mesh). Although no major difference was reported between surface water conservation and cartridge storage for the selected herbicides. Nevertheless, many methods for the ultratrace analysis of pharmaceuticals and other emerging contaminants are trying to move away from off line solid-phase extractions and cartridges [9]; it is therefore even more pertinent to determine the procedural limits of how natural samples should be preserved when using an automated SPE system.

Few studies consider the stability of estrogens and progestogens in surface waters. Indeed, Baronti and coworkers [10] reported that the addition of $1 \%$ of formaldehyde to water samples seem to prolong the stability of estrogens. Except for estrone, a significant loss of estrogens occurred after 60 days of storage. In addition, it was demonstrated that formaldehyde added to water was able to slow but not definitively block bacterial activity [11]. Labadie and co-workers [12] suggested that formaldehyde $(1 \%, v / v)$ must be added to the effluents samples immediately after collection. Furthermore, Vanderford et al [13] tested the preservation of samples for the trace analysis of 27 compounds including estrogens. The results showed that $1 \%$ of formaldehyde added to water was able to prolong estrogens stability but could affect the stability of other compounds. Therefore, those authors concluded that sulfuric acid is the most effective and least destructive preservative agent for their study.

However, it is essential to know how long the content of a sample may remain stable before analysis. In this context, the objective of this study was to provide data concerning the stability under normal operating conditions and variable time of storage for a suite of pharmaceutical and personal care products (PPCP), pesticides, estrogens and progestogens in natural surface waters. These compounds were selected based on their high consumption and their reported occurence in wastewater and drinking water sources [14-16]. These compounds were analyzed by a multi-residue method using an on-line solid-phase extraction combined with liquid chromatography tandem mass spectrometry (SPE-LC-MS/MS), with two ionization sources: ESI interface applied for analysis of pharmaceuticals and pesticides [14], while an APPI interface was applied for the analysis of steroids (estrogens and progestogens) [15].

\section{Experimental}

\section{Reagents and chemicals}

Analytical standards such as PPCP, pesticides and hormones were purchased as powders from Sigma-Aldrich Canada (Oakville, ON, Canada) (98-99\% pure). Internal standards included $\left[{ }^{13} \mathrm{C}_{3}\right]$-estradiol, $\left[{ }^{13} \mathrm{C}_{3}\right]$-caffeine and $\left[{ }^{13} \mathrm{C}_{3}\right]$-atrazine and were supplied by ACP Chemical Inc. (Montréal, Qc, Canada). All solvents (trace analysis grade), $0.1 \%$ formic acid in water and LC-grade water were purchased from Baker (Quebec, Canada).

\section{Standards solutions}

Due to the solubility properties of these compounds in methanol, individual stock solutions of the analytes were initially prepared at $1000 \mathrm{mg} \mathrm{l}^{-1}$ by dissolving $25 \mathrm{mg}$ of each compound in $25 \mathrm{ml}$ of methanol and stored in the dark at $-20^{\circ} \mathrm{C}$. Standard mixtures of the compounds were prepared in methanol at different concentrations by appropriate dilutions of the individual stock solutions.

In order to increase the accuracy of the analytical data, stable isotopically-labeled standards were added to the initial water samples. $\left[{ }^{13} \mathrm{C}_{3}\right]$-atrazine served as the internal standard for the quantification of pesticides, $\left[{ }^{13} \mathrm{C}_{3}\right]-$ caffeine for the quantification of pharmaceuticals and personal care products and finally $\left[{ }^{13} \mathrm{C}_{3}\right]$-estradiol served for the quantification of estrogens and progestogens.

Working solutions of the target compounds and internal standards were prepared in the matrix to build the calibration curve. The concentrations of the analytes ranged from 0 to $100 \mathrm{ng} \mathrm{L}^{-1}$ and the internal standards concentrations were set at $70 \mathrm{ng} \mathrm{L}^{-1}$.

\section{Sampling and filtration}

Homogeneous surface water samples (11) were collected in January 2008 from one of Montreal drinking raw water intake. The characteristics of selected surface water are shown in Table 2.

\section{Storage studies}

The stability of selected compounds in surface water was evaluated for storage in refrigerated amber glass bottles. For this purpose, the matrix samples obtained were filtered through a $0.45-\mu \mathrm{m}$ PTFE membrane (Millipore) to remove particulate matter and other suspended solids, and then acidified.

Table 2: Characteristics of the surface water sample tested.

\begin{tabular}{ccccc}
\hline Surface water & $\mathbf{p H}$ & Conductivity $(\boldsymbol{\mu S} / \mathbf{c m})$ & Total Organic Carbon (mg/l) & Turbidity (TNU) \\
\hline 16 Jan 08 & 8.33 & 299 & 2.6 & 1.2 \\
\hline
\end{tabular}




\section{Apparatus}

\section{On line SPE-LC-MS/MS Analysis}

Briefly, the LC system consists of a binary pump (a Surveyor LC-pump) and a quaternary pump (Surveyor MS Pump Plus - Thermo Fisher Scientific, Waltham, MA, USA). A six-port switching valve was used for all analysis. The sample was injected using a Surveyor autosampler fitted with a 1-mL sample loop, through the valve into the extraction column (Hypersil GOLDTM column, $12 \mu \mathrm{m}$, $20 \mathrm{~mm} \times 2.1 \mathrm{~mm}$ i.d). The extraction column was then loaded for $1.4 \mathrm{~min}$ (flow rate $1 \mathrm{ml} \mathrm{min}^{-1}$ ) with water/formic acid solution ( $\mathrm{pH} 2.6$ ). The valve position was then switched to allow the bound material to be eluted from the extraction cartridge in back flush mode directly onto the analytical column with $0.1 \%$ formic acid-methanol $(95: 5 \mathrm{v} / \mathrm{v})$ at a flow rate of $200 \mu \mathrm{l} \mathrm{min}^{-1}$. After $17 \mathrm{~min}$, the valve position was again switched to allow the extraction column to be re-equilibrated at a flow rate of $1 \mathrm{ml} \mathrm{min}^{-1}$ with water/formic acid solution $(\mathrm{pH} 2.6)$. The total run time per sample was 20 min for pharmaceuticals and pesticides and 15 min for steroidal hormones. The LC was performed using a 3- $\mu \mathrm{m}$ Hypersil GOLD column, $50 \mathrm{~mm}$ $\times 2.1 \mathrm{~mm}$ i.d. (Thermo Fisher Scientific, Waltham, MA, USA) preceded by a guard column $(2 \times 2 \mathrm{~mm}, 5 \mu \mathrm{m})$. The extraction and analytical columns were kept at ambient temperature. For estrogens and progestogens, the same procedural steps were carried out, except the analytical column temperature $\left(40^{\circ} \mathrm{C}\right)$, and variations for the elution and separation gradients.

A TSQ Quantum Ultra AM Mass Spectrometer (Thermo Fisher Scientific, Waltham, MA, USA) tandem triple quadrupole mass spectrometry fitted with either an ESI or APPI source was used for detection. The instrument was operated in positive ionization mode and was directly coupled to the HPLC system at a flow rate of 200 $\mu \mathrm{l} \mathrm{min}{ }^{-1}$. Sample analysis was performed in the selective reaction monitoring mode (SRM). System control and data acquisition was performed using the Analyst Xcalibur software (rev. 2.0 SP2, Thermo Fisher Scientific). Further methodological details are available [14-16].

\section{Statistical analysis}

A one-way analysis of variance (ANOVA Tukey's-b post hoc) test was used to evaluate whether the means of control and experiment groups are statistically different. All treatments were carried out in triplicate, and data in Figure 1 are expressed as mean recoveries with relative standard deviations. Statistical analysis was performed using SPSS 13 software (SPSS Inc., Chicago, IL), significance was set at the $\mathrm{P}<0.05$ probability level.

\section{Quantification and data analysis}

Standard solutions used for quantification were also preconcentrated using the same procedure as the samples. Before each analysis, the IS was added to correct for vari-
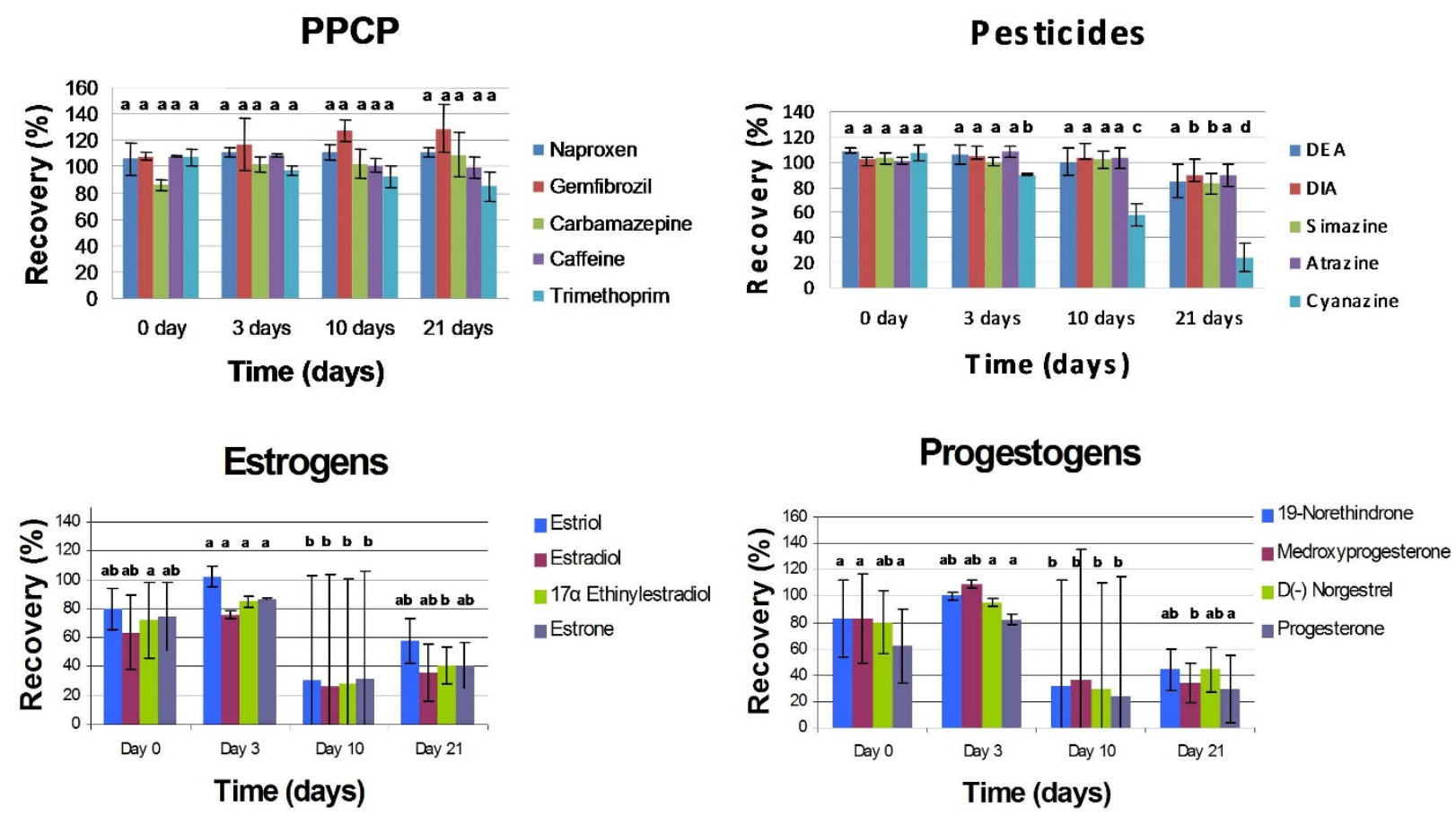

Figure 1 Effect of various storage periods on recovery (\%) of pharmaceuticals, pesticides, hormones (synthetic and natural estrogens and progestogens) dissolved in surface water at $\mathbf{1 0 0} \mathbf{~ n g ~ I - 1 ~ L e v e l . ~ T h e ~ e r r o r ~ b a r ~ l e n g t h s ~ r e p r e s e n t ~ t h e ~ r e l a t i v e ~ s t a n d a r d ~ d e v i a t i o n s ~ o n ~ m e a n ~ r e c o v e r y ~}$ (recovery for three replicates). Bars with the same letters are not statistically different $p>0.05$ level using a Tukey's-b post hoc test. 
ation in sample recovery and instrumental performance. Peak areas of analytes were normalized to those of their IS. Five specific concentrations of native analytes ranged from 0 to $100 \mathrm{ng} \mathrm{l}^{-1}$ with a fixed addition at $70 \mathrm{ng} \mathrm{l}^{-1}$ of a stable isotopically-labeled standard injected for each analysis to build up a calibration curve $\left(\mathrm{r}^{2}\right.$ values were at least $>0.988$ ). Areas of the analytes and IS were calculated using the LCquanTM 2.5 software (Thermo Fisher Scientific inc).

\section{Results and discussion}

Schwartz and co-workers [17] mentioned that bacteria cannot survive in organic solvents, to improve the stability of these target compounds in surface water samples, we added $2.5 \%$ of methanol to fresh working solutions previously acidified at $\mathrm{pH} 2.8$ and spiked at $100 \mathrm{ng} \mathrm{l}^{-1}$ level.

\section{Pharmaceutical and personal care products}

For any pollutant, including pharmaceuticals, biotic transformations in surface waters may occur via hydrolysis and photolysis. Most pharmaceuticals are usually designed for oral intake and generally resistant to hydrolysis, so quite often, the primary pathway for their abiotic transformation in surface waters is direct or indirect photolysis [18].

During the storage stability study, the ANOVA statistical analysis shows that no significant losses were observed after 21 days of storage for all pharmaceutical and personal care products studied including carbamazepine, naproxen, gemfibrozil and caffeine over the entire period of storage in surface water at $40^{\circ} \mathrm{C}$, the recoveries obtained ranged from 85 to $129 \%$ (Figure 1). The stability of these compounds can be probably attributed to their low vapor pressure and their medium water solubility (up to $40 \mathrm{mg} \mathrm{l}^{-1}$ ), both of these factors probably also contribute to the stability of many pesticides in surface waters [4].

\section{Pesticides}

The pesticides included in this study were tested at concentrations equal to $100 \mathrm{ng} \mathrm{l}^{-1}$, the maximum allowed by EU legislation [8]. It was demonstrated that the pesticides can be degraded during storage by such processes as hydrolysis or microbial decomposition. In order to evaluate optimum conditions for storing the pesticides in matrix water before analysis, different storage periods were studied.

Figure 1 shows that no statistically significant losses were observed for atrazine and its first degradation intermediate DEA after 21 days of storage under our experimental conditions, these results are in agreement with Aguilar et al. [19]. While significant losses of DIA and simazine were observed after 10 days of storage, there was only a $14 \%$ reduction for DIA and a $17 \%$ reduction for simazine. These results can probably be attributed (amongst others things), to the presence of $\mathrm{H}+$ ions which contribute to degradation of these compounds by hydrolysis because it has been shown that at $\mathrm{pH}>4$ (which we would normally expect to find in the aquatic environment) hydrolysis of simazine is negligible [20]. In addition, Lyytikäinen and co-workers have demonstrated that at $\mathrm{pH} 8$ after 28 days of storage, $10 \%$ loss of simazine occurred in water [21].

In the case of cyanazine, high instability was detected over the whole duration of storage. This is not a surprise given the recognized sensitivity of cyanazine to hydrolysis in acidic medium which produces a carboxylic acid and another product from the cleavage of the secondary amine [22]. Cyanazine is also much less stable than atrazine and simazine in surface waters of the USA, and this has been attributed to the oxidation of the cyanazine [20]. Furthermore, the poor stability of cyanazine can also be attributed to its high water solubility, at up to $700 \mathrm{mg} \mathrm{l}^{-1}$ [3]. The chromatograms corresponding to the preconcentration of $1 \mathrm{ml}$ of surface water sample spiked at 100 ng $\mathrm{l}^{-1}$ level with the pharmaceuticals and pesticides obtained after 21 days of storage at $40^{\circ} \mathrm{C}$ are given in Figure 2 .

\section{Estrogens and progestogens}

In the case of feminizing steroids, serious stability problems arise during sample storage in the environmental matrix. The ANOVA analysis shows that in surface water samples, all the estrogens and the progestogens present statistically significant losses varying from 63 to $72 \%$ after 10 days of storage (Figure 1 ).

No oxidation of estradiol (E2) to estrone (E1) was apparent given that the elimination rates are almost identical. These losses can be linked to the physicochemical properties of these compounds. Also, the disappearance from solution can alternatively be attributed to the adsorption of these compounds onto suspended particulate matter and this would therefore reduce their concentrations in the aqueous phase $[23,24]$ and would depend on matrix characteristics such as total organic carbon, turbidity and oxygen consumption. Figure 3 represents the chromatograms of these compounds detected after 3 days of storage in surface water samples.

\section{Conclusions}

In conclusion, 'immediate analysis' is the best way to obtain the most accurate data, but in practice this is not always possible. Therefore, it is often necessary to store surface water samples before the quantification of pharmaceutical products, pesticides and steroidal hormones.

For pharmaceutical compounds and for most pesticides tested, the compounds are quite stable to degradation 


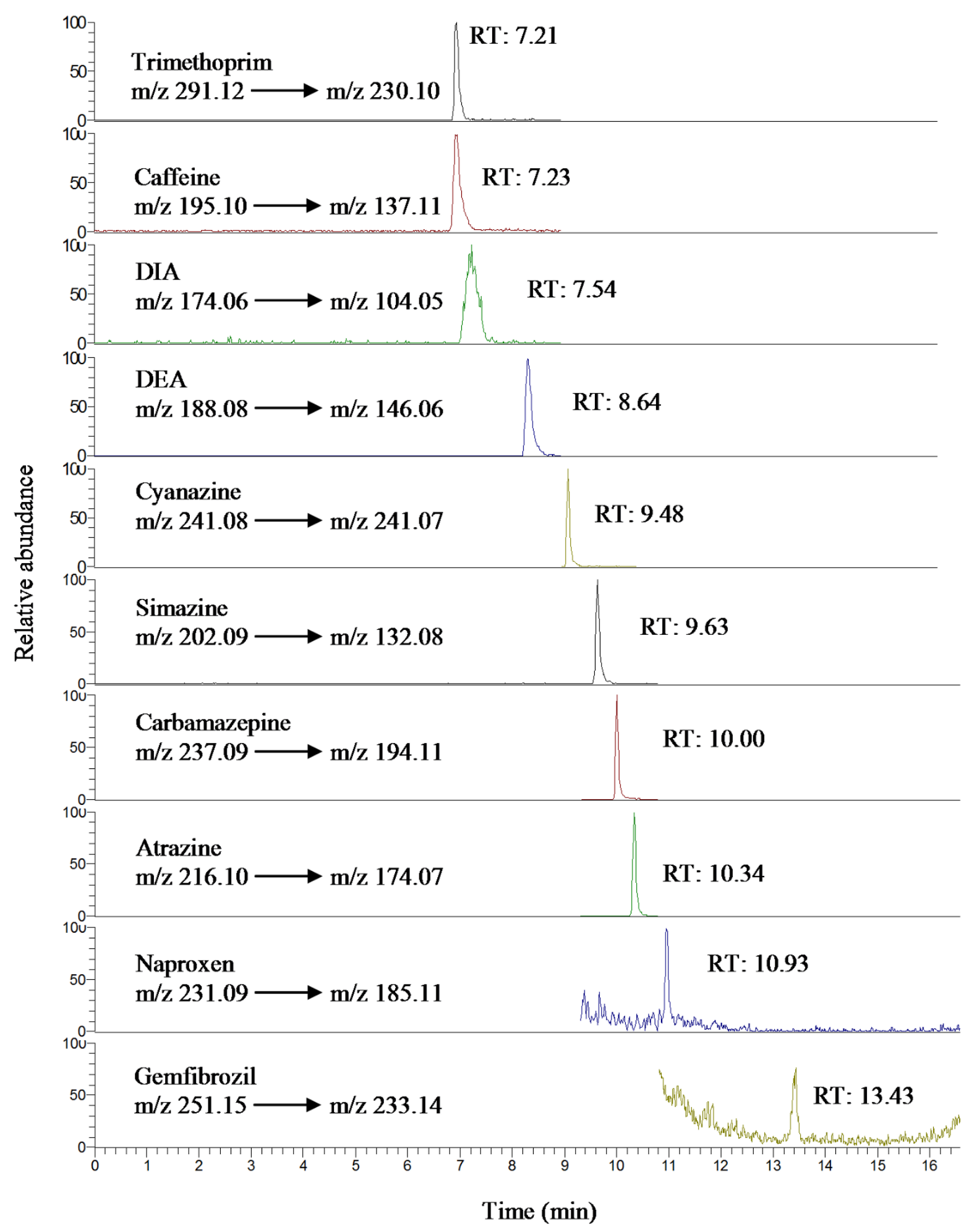

Figure 2 SPE-LC-ESI-MS/MS SRM chromatograms of pharmaceuticals and pesticides obtained after 21 days of storage at $4^{\circ} \mathrm{C}$ in surface water $(\mathrm{pH}=2.8)$ spiked at $100 \mathrm{ng} \mathrm{l}^{-1}$ level and with $2.5 \%$ of $\mathrm{MeOH}$ added 


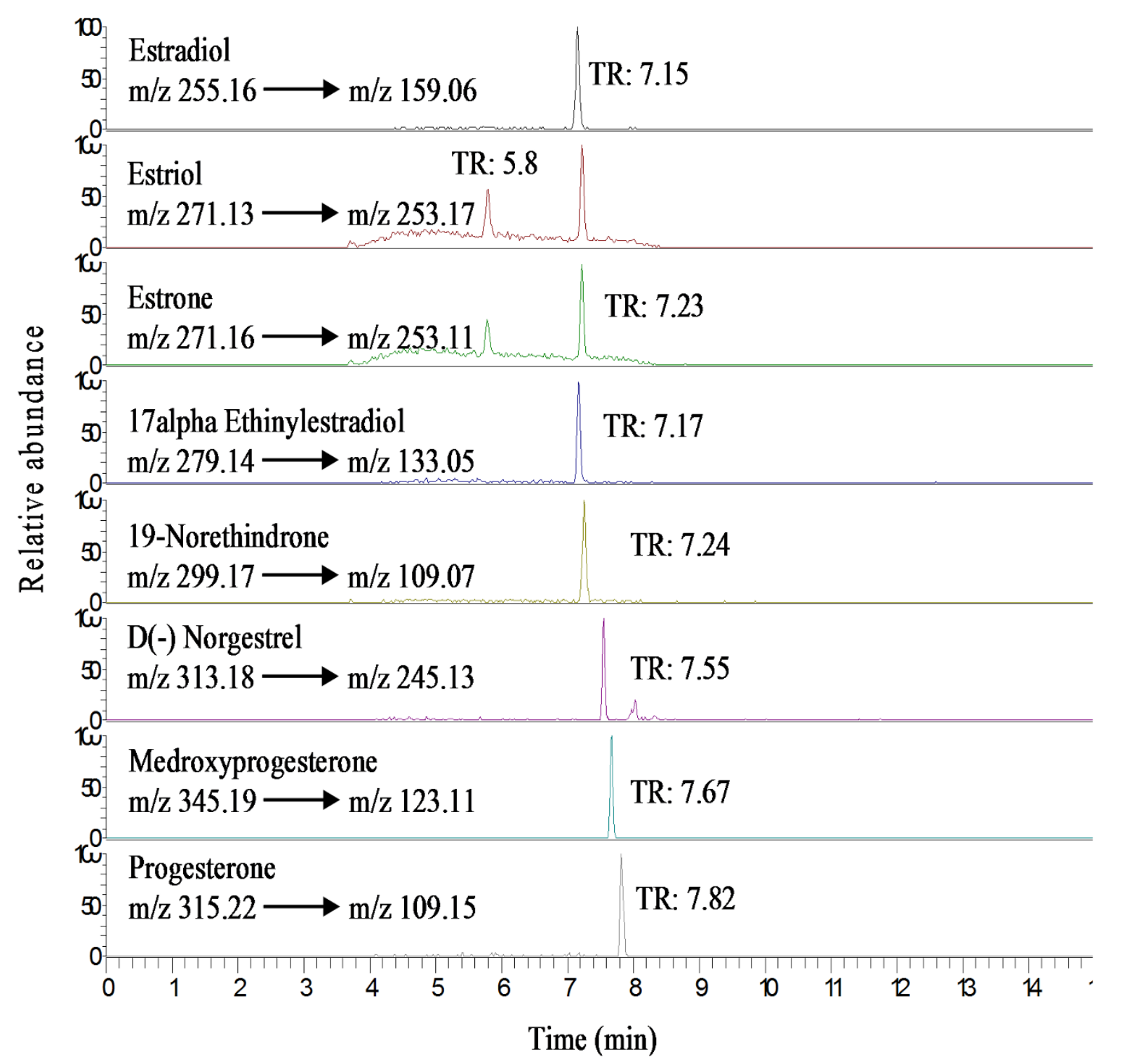

Figure 3 SPE-LC-APPI-MS/MS SRM chromatograms of estrogens and progestogens obtained after 3 days of storage at $4^{\circ} \mathrm{Cin}$ surface water $(\mathrm{pH}=2.8)$ spiked at $100 \mathrm{ng} \mathrm{l}^{-1}$ and $2.5 \%$ of $\mathrm{MeOH}$ was added

when quickly filtered, acidified and refrigerated. It seems feasible to store natural samples for up to three weeks without significant losses of analyte, except for cyanazine (and presumably other hydrolysis-prone compounds).

In the case of the steroidal hormones, both estrogens and progestogens, high instability and severe losses were observed during sample storage. Therefore, the degradation of these products is linked to their physico-chemical properties and the type of matrix. Because of this, we would recommend to analyse for steroidal hormones ideally within three days of collection and certainly within less than a 1 week, unless stability studies specific to the actual experimental conditions are verified.
Competing interests

The authors declare that they have no competing interests.

\section{Authors' contributions}

CDP carried out some of the initial laboratory work and data analysis. KA completed the laboratory work, all of the MS analysis and data treatment and drafted the manuscript. MP and SS conceived the study, SS coordinated the study and edited the text. All authors have read and approved the final manuscript.

\section{Acknowledgements}

This work was made possible through the financial support of the Natural Sciences and Engineering Research Council of Canada (NSERC), the NSERC Industrial Chair on Drinking Water at the École Polytechnique de Montréal and equipment grants from the Canadian Foundation for Innovation. 


\section{Author Details}

'Département de chimie, Université de Montréal, Montréal, QC, Canada and ${ }^{2}$ Chaire CRSNG en Eau Potable, Département des génies civil, géologique et des mines, École Polytechnique de Montréal, Canada

Received: 10 December 2009 Accepted: 19 April 2010

Published: 19 April 2010

\section{References}

1. Hengel MJ, Mower CR, Shibamoto T: New method for analysis of pyrethroid insecticides: Esfenvalerate, cis-permethrin, and transpermethrin, in surface waters using solid-phase extraction and gas chromatography. Bull Environ Contam Toxicol 1997, 59:171-178.

2. Ferrer I, Barcelo D: Stability of pesticides stored on polymeric solidphase extraction cartridges. J Chromatogr A 1997, 778:161-170.

3. Barcelo D, Alpendurada MF: A review of sample storage and preservation of polar pesticides in water samples. Chromatographia 1996, 42:704-712.

4. Casas V, Llompart M, Garcia-Jares C, Cela R, Dagnac T: Effects of sample pretreatment and storage conditions in the determination of pyrethroids in water samples by solid-phase microextraction and gas chromatography-mass spectrometry. Anal Bioanal Chem 2007, 387:1841-1849.

5. de la Colina C, Sanchez-Rasero F, Dios G, Romero E, Pena A: Effect of storage on the recovery of different types of pesticides ssing a solidphase extraction method. Analyst 1997, 122:7-11.

6. Mouvet C, Jeannot R, Riolland H, Maciag C: Stability of isoproturon, bentazone, terbuthylazine and alachlor in natural groundwater, surface water and soil water samples stored under laboratory conditions. Chemosphere 1997, 35:1083-1097.

7. Berrueta LA, Gallo B, Vicente F: A review of solid phase extraction: Basic principles and new developments. Chromatographia 1995, 40:474-483.

8. Sabik H, Jeannot R, Sauvard E: Stability of herbicides and their degradation products on graphitized carbon black extraction cartridges used for large volumes of surface water. Analysis 2000, 28:835-842.

9. Segura PA, Gagnon C, Sauvé S: A fully automated on-line preconcentration and liquid chromatography-tandem mass spectrometry method for the analysis of anti-infectives in wastewaters. Anal Chim Acta 2007, 604:147-157.

10. Baronti C, Curini R, D'Ascenzo G, di Corcia A, Gentili A, Amperi R: Monitoring natural and synthetic estrogens at activated sludge sewage treatment plants and in a receiving river water. Environ Sci Technol 2000, 34:5059-5066.

11. Fendinger NJ, Begley WM, MCAvoy DC, Eckhoff WS: Determination of alkyl sulfate surfactants in natural waters. Environ Sci Technol 1992, 26:2493-2498.

12. Labadie P, Budzinski H: Development of an analytical procedure for determination of selected estrogens and progestagens in water samples. Anal Bioanal Chem 2005, 381:1199-1205.

13. Vanderford BJ, Pearson RA, Rexing DJ, Snyder SA: Analysis of endocrine disruptors, pharmaceuticals, and personal care products in water using liquid chromatography/tandem mass spectrometry. Anal Chem 2003, 75:6265-6274

14. Viglino L, Aboulfadl K, Daneshvar Mahvelat A, Prévost M, Sauvé S: On-line solid phase extraction and liquid chromatography/tandem mass spectrometry to quantify pharmaceuticals, pesticides and some metabolites in wastewaters, drinking, and surface waters. J Environ Monit 2007, 10:482-489.

15. Viglino L, Aboulfadl K, Prévost M, Sauvé S: Analysis of natural and synthetic estrogenic endocrine disruptors in environmental waters using on-line preconcentration coupled to LC-APPI-MS/MS. Talanta 2008, 76:1088-1096.

16. Garcia-Ac A, Segura PA, Viglino L, Fürtos A, Gagnon C, Prévost M, Sauvé S: On-line solid-phase extraction-LC-MS/MS using large volume injections: validation for trace organic contaminants in surface and drinking water. J Chromatogr A 2009, 1216:8512-8527.

17. Schwartz RD, Williams AL, Hutchinson DB: Microbial production 4,4'dihydroxybiphenyl: biphenylhydroxylation by fungi. Appl Environ Microbiol 1980, 39:702-708.
18. Andreozzi R, Raffaele M, Nicklas P: Pharmaceuticals in STP effluents and their solar photodegradation in aquatic environment. Chemosphere 2003, 50:1319-1330.

19. Aguilar C, Ferrer I, Borrull F, Marcé RM, Barcelo D: Monitoring of pesticides in river water based on samples previously stored in polymeric cartridges followed by on line solid-phase extraction-liquid chromatography-diode array detection and confirmation by atmospheric pressure chemical ionization mass spectrometry. Anal Chim Acta 1999, 386:237-248.

20. Comber DW: Abiotic persistence of atrazine and simazine in water. Pesticide Science 1999, 55:696-702.

21. Lyytikäinen M, Kukkomen JVK, Lydy MJ: Analysis of pesticides in water and sediment under different storage conditions using gas chromatography. Arch Environ Contam Toxicol 2003, 44:437-444.

22. Cotruvo J, Gordon G, Bull R: Analytical Support Part Il-Shane Snyder, The Rate of Bromate Decomposition in the Simulated Human Stomach and Associated Studies, Final Project Report 2005 [http://www.nwri-usa.org/pdfs/ 2005\%20Bromate\%20Decomposition\%20Report.pdf. National Water Research Institute

23. Ying GG, Kookana RS, Ru YJ: Occurrence and fate of hormone steroids in the environment. Environ Internat 2002, 28:545-551.

24. Kuster M, de Alda MJL, Barcelo D: Analysis and distribution of estrogens and progestogens in sewage sludge, soils and sediments. Tr Anal Chem 2004, 23:790-798

25. Avdeef A: Solubility of sparingly-soluble ionizable drugs. Advanced Drug Delivery Reviews 2007, 59:568-590.

26. Muñoza I, Gómez-Ramosa MJ, Agüera A, Fernández-Alba AR, García-Reyes JF, Molina-Díaz A: Chemical evaluation of contaminants in wastewater effluents and the environmental risk of reusing effluents in agriculture. Tr Anal Chem 2009, 28:676-694.

doi: 10.1186/1752-153X-4-10

Cite this article as: Aboulfadl et al., Time-dependent integrity during storage of natural surface water samples for the trace analysis of pharmaceutical products, feminizing hormones and pesticides Chemistry Central Journal 2010, 4:10

\section{Publish with ChemistryCentral and every scientist can read your work free of charge \\ "Open access provides opportunities to our colleagues in other parts of the globe, by allowing anyone to view the content free of charge." \\ W. Jeffery Hurst, The Hershey Company. \\ - available free of charge to the entire scientific community \\ - peer reviewed and published immediately upon acceptance \\ - cited in PubMed and archived on PubMed Central \\ - yours - you keep the copyright \\ Submit your manuscript here \\ http://www.chemistrycentral.com/manuscript/ \\ ChemistryCentral}

